\title{
A Randomized Trial of Hyperimmune Globulin to Prevent Congenital Cytomegalovirus
}

\author{
Maria Grazia Revello, M.D., Tiziana Lazzarotto, Ph.D., Brunella Guerra, M.D., \\ Arsenio Spinillo, M.D., Enrico Ferrazzi, M.D., Alessandra Kustermann, M.D., \\ Secondo Guaschino, M.D., Patrizia Vergani, M.D., Tullia Todros, M.D., \\ Tiziana Frusca, M.D., Alessia Arossa, M.D., Milena Furione, M.D., \\ Vanina Rognoni, M.D., Nicola Rizzo, M.D., Liliana Gabrielli, M.D., \\ Catherine Klersy, M.D., and Giuseppe Gerna, M.D., for the CHIP Study Group*
}

ABSTRACT

The authors' affiliations are listed in the Appendix. Address reprint requests to Dr. Revello at the Fondazione IRCCS Policlinico San Matteo, P.le Golgi 19, 27100 Pavia, Italy, or at mg.revello@smatteo.pv.it.

* Members of the Congenital HCMV Infection Prevention (CHIP) Study Group are listed in the Supplementary Appendix, available at NEJM.org.

N Engl J Med 2014;370:1316-26. DOI: 10.1056/NEJMoa1310214

Copyright (๑) 2014 Massachusetts Medical Society.

\section{BACKGROUND} tion significantly reduced the rate of intrauterine transmission, from $40 \%$ to $16 \%$.

\section{METHODS}

Congenital infection with human cytomegalovirus (CMV) is a major cause of morbidity and mortality. In an uncontrolled study published in 2005, administration of CMV-specific hyperimmune globulin to pregnant women with primary CMV infec-

We evaluated the efficacy of hyperimmune globulin in a phase 2, randomized, placebo-controlled, double-blind study. A total of 124 pregnant women with primary CMV infection at 5 to 26 weeks of gestation were randomly assigned within 6 weeks after the presumed onset of infection to receive hyperimmune globulin or placebo every 4 weeks until 36 weeks of gestation or until detection of CMV in amniotic fluid. The primary end point was congenital infection diagnosed at birth or by means of amniocentesis.

\section{RESULTS}

A total of 123 women could be evaluated in the efficacy analysis (1 woman in the placebo group withdrew). The rate of congenital infection was 30\% (18 fetuses or infants of 61 women) in the hyperimmune globulin group and $44 \%$ ( 27 fetuses or infants of 62 women) in the placebo group (a difference of 14 percentage points; $95 \%$ confidence interval, -3 to $31 ; \mathrm{P}=0.13$ ). There was no significant difference between the two groups or, within each group, between the women who transmitted the virus and those who did not, with respect to levels of virus-specific antibodies, T-cell-mediated immune response, or viral DNA in the blood. The clinical outcome of congenital infection at birth was similar in the two groups. The number of obstetrical adverse events was higher in the hyperimmune globulin group than in the placebo group (13\% vs. $2 \%$ ).

\section{CONCLUSIONS}

In this study involving 123 women who could be evaluated, treatment with hyperimmune globulin did not significantly modify the course of primary CMV infection during pregnancy. (Funded by Agenzia Italiana del Farmaco; CHIP ClinicalTrials.gov number, NCT00881517; EudraCT no. 2008-006560-11.) 
VERY YEAR, APPROXIMATELY 0.6\% OF ALL newborns in the United States and the European Union are congenitally infected with human cytomegalovirus (CMV). ${ }^{1,2}$ Approximately $20 \%$ of these infected newborns are symptomatic at birth or will have sequelae such as sensorineural hearing loss, cognitive defects, and motor defects. ${ }^{3}$ Primary CMV infection that develops in a woman during pregnancy confers the highest risk of congenital infection and disease. ${ }^{4}$ Identification of pregnant women with primary CMV infection is feasible by means of detection of virus-specific IgM and low IgG avidity. However, the unavailability of a therapeutic intervention of proven efficacy in the case of documented maternal infection has been considered to be a major obstacle to the implementation of routine serologic screening of pregnant women.

In 2005, a nonrandomized study showed that when CMV-specific hyperimmune globulin was administered to pregnant women with primary infection, the rate of mother-to-fetus transmission decreased significantly, from $40 \%$ to $16 \%(\mathrm{P}=0.04)$, and the risk of congenital disease also decreased significantly, from $50 \%$ to $3 \%(\mathrm{P}<0.001) .^{5}$ Other nonrandomized studies have shown a decrease in the number of congenitally infected infants born to mothers who had been treated with hyperimmune globulin or improved outcomes in CMV-infected infants. ${ }^{6-9}$ We designed the current randomized, controlled clinical trial to verify the previously reported efficacy of CMVspecific hyperimmune globulin in preventing fetal infection. ${ }^{10}$

\section{METHODS}

\section{STUDY OVERSIGHT}

The Congenital HCMV Infection Prevention (CHIP) trial was a phase 2, double-blind, placebo-controlled, parallel-group trial. We conducted the trial at 11 centers in Italy. The study, which was supported entirely by Agenzia Italiana del Farmaco in Rome, ${ }^{11}$ was approved by the ethics committees at each participating center. Participants provided written informed consent before study entry. A contract research organization (Clinical Research Technology, Salerno, Italy) was responsible for the regulatory aspects of the study, verification of source documents, and monitoring of safety.

\section{STUDY END POINTS}

The primary end point was the number of infected fetuses or newborns of mothers who received treatment with hyperimmune globulin as compared with the number of infected fetuses or newborns of mothers who received placebo. Secondary end points included CMV DNA level, response to the study drug as assessed by means of an enzyme-linked immunosorbent assay (ELISA) and measurements of neutralizing antibodies, lymphocyte subpopulations, and CMV-specific T-cell response; virologic and immunohistologic findings in placentas; ultrasonographic findings in fetuses; clinical outcomes of congenital CMV infection within the first 2 weeks of life; and safety of CMV-specific hyperimmune globulin. Details of the study design are provided in the protocol and the Supplementary Appendix, both of which are available with the full text of this article at NEJM.org.

\section{PARTICIPANTS}

Pregnant women who had a primary infection at 5 to 26 weeks of gestation, with a presumed onset of infection within the previous 6 weeks, were invited to participate in the study. Details regarding the identification of women with recent CMV infection, as well as the eligibility criteria, are provided in the Supplementary Appendix. The virology units of Fondazione Istituto di Ricovero e Cura a Carattere Scientifico (IRCCS) Policlinico San Matteo in Pavia, Italy, and Sant'Orsola Malpighi Hospital in Bologna, Italy, served as the reference diagnostic centers for confirmation of primary CMV infection.

\section{RANDOMIZATION}

Participants were randomly assigned, in a 1:1 ratio, to receive hyperimmune globulin or placebo. Randomization was performed with the use of a computer-based randomization list that was generated by the study statistician and provided to the study pharmacists by the contract research organization. Randomization, which was performed with the use of Stata software, was balanced in blocks of various sizes, with stratification according to center. Participants, personnel administering the study drugs, physicians, technicians, and the study statistician were unaware of the studygroup assignments until completion of the study and retrospective analysis of the samples. 
The hyperimmune globulin preparation (purchased from Cytotect, Biotest Pharma, which had no other role in the study) is a ready-for-use solution that contains $50 \mathrm{U}$ of anti-CMV IgG antibody per milliliter (100 $\mathrm{mg}$ of protein of plasma origin per milliliter, resulting in $\geq 95 \%$ IgG). The dose was $100 \mathrm{U}(2.0 \mathrm{ml})$ per kilogram of body weight administered intravenously (see the Supplementary Appendix for details and for the lot numbers of the preparations). The placebo was a $0.9 \%$ saline solution and was given intravenously at the same dose (2.0 ml per kilogram) as the active drug. Infusion bags containing the required volume of drug or placebo were prepared at each center by the study pharmacist and sealed with aluminum foil. Only the randomization number was written on the label. Pregnant women received hyperimmune globulin or placebo every 4 weeks until 36 weeks of gestation, detection of CMV in the amniotic fluid (in the case of women who underwent amniocentesis), or spontaneous termination of the pregnancy. Before each infusion, blood samples were obtained for retrospective analysis.

\section{LABORATORY TESTS}

Levels of virus-specific IgG and IgM antibodies were determined with the use of the ETI-CYTOK-G PLUS and ETI-CYTOK-M reverse PLUS ELISAs, respectively (DiaSorin), and IgG avidity was determined with the use of the CMV IgG avidity test (Radim). Neutralizing antibodies against the AD169 strain of CMV in human fibroblasts and the VR1814 strain of CMV in epithelial (spontaneously arising retinal pigment epithelial [ARPE]19) cells were assessed as described previously. ${ }^{12}$ Viral DNA in the blood was determined with the use of a real-time polymerase-chain-reaction (PCR) assay (CMV ELITe MGB Kit, ELITechGroup). Positive samples with less than 396 IU per milliliter were assigned an arbitrary value of 200 IU. Antigenemia was determined as described previously. ${ }^{13}$ Rapid isolation ${ }^{14}$ of the virus from amniotic fluid or urine samples and real-time PCR analysis of those samples were used for the diagnosis of congenital infection. Viral load in placentas was determined as described previously. ${ }^{15}$

$\mathrm{CD} 3+, \mathrm{CD} 4+, \mathrm{CD} 8+, \mathrm{CD} 56+$, and CD19+ lymphocyte counts were determined at each study visit. Surface phenotype (in the case of CD4+ and CD8+ lymphocytes) as well as interferon- $\gamma-$ producing CMV-specific $\mathrm{T}$ cells were determined retrospectively by means of flow cytometry, as described previously. ${ }^{16}$

\section{DIAGNOSIS AND DATING OF PRESUMED ONSET OF MATERNAL INFECTION}

The diagnosis of primary CMV infection was based on seroconversion (i.e., an appearance of virus-specific antibodies in a previously seronegative woman) or the concomitant presence of CMV-specific IgM antibodies and low IgG avidity. The onset of infection was established on the basis of clinical symptoms, when they were present. In the case of asymptomatic seroconversion, onset was arbitrarily set midway between the time of the last seronegative serum sample and the first seropositive serum sample. In addition, one or more of the following findings were considered to be consistent with an onset of infection less than 6 weeks previously: an IgM value that was 10 or more times the cutoff value, IgG avidity of less than $15 \%$ (avidity of $<35 \%$ indicates a primary infection acquired $<12$ weeks earlier), or detection of pp65 antigenemia.

\section{STATISTICAL ANALYSIS}

We estimated that we would need to enroll 60 women in each group for the study to have $80 \%$ power to confirm the reduction in congenital infection from $40 \%$ to $16 \%$ reported by Nigro et al., 5 at a 5\% type I error rate and assuming a 10\% rate of withdrawal. A 36-month enrollment period was anticipated for recruiting this number of patients. The statistical analyses followed the intention-to-treat principle for the efficacy end points and the on-treatment principle for the safety end points. The analysis population consisted of all women who underwent randomization and were assessed for the primary end point. The incidence of the primary end point was compared between the two study groups with the use of Fisher's exact test, and the difference in risk was calculated together with its $95 \%$ confidence interval. We used Fisher's exact test to compare categorical secondary end points, the MannWhitney $\mathrm{U}$ test to compare continuous secondary end points, and the log-rank test to compare time-to-event secondary end points. A futility analysis was planned after half the study participants had reached the primary end point, with the aim of recommending the discontinuation of the study if the $95 \%$ confidence interval 


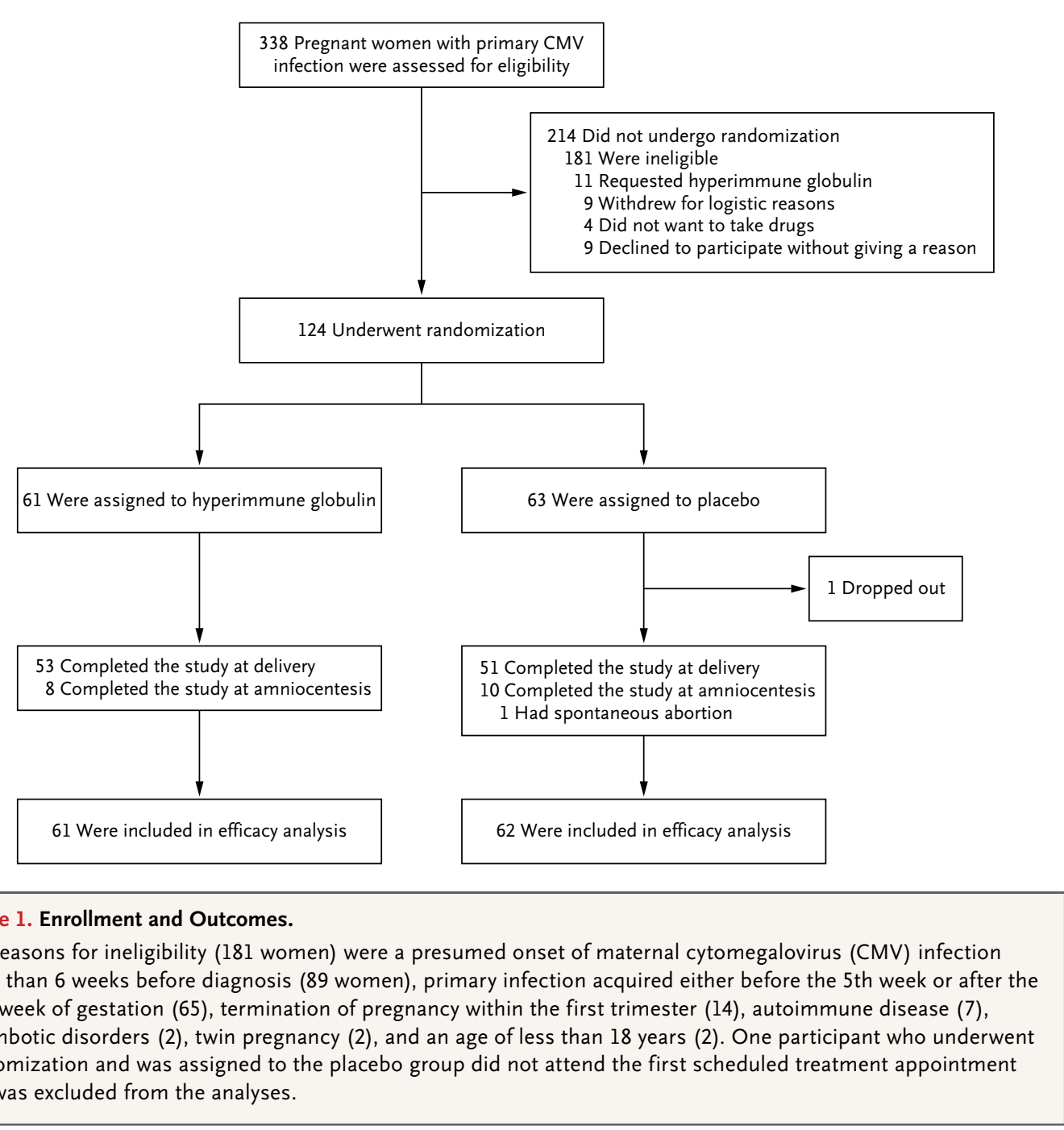

for the difference in risk did not include at least a 10-percentage-point benefit with the active drug. All the analyses were performed with the use of Stata 12 software (StataCorp). A two-sided P value of less than 0.05 was considered to indicate statistical significance.

\section{RESULTS}

\section{ENROLLMENT}

Enrollment took place from June 2009 through March 2011, and the last newborn was examined in November 2011. Of 338 pregnant women who received a diagnosis of primary CMV infection, 181 (54\%) were excluded, and 33 of the 157 eli- gible women (21\%) declined to participate in the study (Fig. 1). Of the 124 women enrolled, 123 completed the study and were included in the efficacy analysis. There were no significant differences between the two groups in any of the baseline characteristics, including the method used for determining the onset of infection (Table 1).

In both groups, the diagnosis of primary infection based on testing for seroconversion was made later during pregnancy than was diagnosis based on CMV-specific IgM antibody level and IgG avidity (14 weeks [range, 7 to 26] vs. 8 weeks [range, 5 to 18] in the hyperimmune globulin group and 17 weeks [range, 6 to 26] vs. 8 weeks [range, 6 to 17] in the placebo group). Overall, 


\begin{tabular}{|c|c|c|}
\hline Variable & $\begin{array}{l}\text { Hyperimmune Globulin } \\
\qquad(\mathrm{N}=61)\end{array}$ & $\begin{array}{l}\text { Placebo } \\
(\mathrm{N}=62)\end{array}$ \\
\hline \multicolumn{3}{|l|}{ Age $-y r$} \\
\hline Median & 33 & 33 \\
\hline Interquartile range & $30-35$ & $29-35$ \\
\hline \multicolumn{3}{|l|}{ Parity - no. (\%) } \\
\hline 0 & $20(33)$ & $18(29)$ \\
\hline$\geq 1$ & $41(67)$ & $44(71)$ \\
\hline \multicolumn{3}{|l|}{ Evidence of infection — no. (\%) } \\
\hline IgG seroconversion & $44(72)$ & $44(71)$ \\
\hline IgM antibodies and low IgG avidity & $17(28)$ & $18(29)$ \\
\hline \multicolumn{3}{|l|}{ Gestation at onset of maternal infection - wk } \\
\hline Median & 12 & 14 \\
\hline Interquartile range & $10-18$ & $8-20$ \\
\hline \multicolumn{3}{|l|}{ Interval between onset of infection and treatment - wk } \\
\hline Median & 5 & 5 \\
\hline Interquartile range & $4-5$ & $4-6$ \\
\hline Presence of symptoms or signs — no. (\%) & $38(62)$ & $34(55)$ \\
\hline \multicolumn{3}{|l|}{ Evidence for dating of presumed onset of infection - no. (\%) } \\
\hline $\begin{array}{l}\text { Seroconversion and symptoms or signs, plus IgM ratio } \geq 10 \text {, } \\
\text { avidity }<15 \% \text {, or positive for pp } 65 \text { antigenemia }\end{array}$ & $24(39)$ & $16(26)$ \\
\hline $\begin{array}{l}\text { Seroconversion without symptoms or signs plus IgM ratio } \geq 10 \text {, } \\
\text { avidity }<15 \% \text {, or positive for pp } 65 \text { antigenemia }\end{array}$ & $11(18)$ & $17(27)$ \\
\hline Seroconversion, with or without symptoms or signs & $9(15)$ & $11(18)$ \\
\hline Avidity $<15 \%$, with or without symptoms or signs & $10(16)$ & $12(19)$ \\
\hline IgM ratio $\geq 10$, with or without symptoms or signs & $4(7)$ & $3(5)$ \\
\hline $\begin{array}{l}\text { Avidity }<15 \% \text { plus IgM ratio } \geq 10 \text { or pp } 65 \text { antigenemia, with or } \\
\text { without symptoms or signs }\end{array}$ & $3(5)$ & $3(5)$ \\
\hline
\end{tabular}

* There were no significant differences between the two groups in any of the baseline characteristics.

72 of the 123 women with primary infection (59\%) reported symptoms (45 women), had abnormal laboratory findings ( 13 women, 8 with abnormal liver enzyme levels and 5 with lymphocytosis), or both (14 women with symptoms and abnormal liver enzyme levels) that were compatible with primary CMV infection. Fever, asthenia, and an influenza-like syndrome, together with abnormal liver enzyme levels, were the symptoms and signs reported most frequently.

\section{INFUSIONS}

A total of 271 infusions were administered in the hyperimmune globulin group, and 254 in the placebo group. The median number of infusions received by each woman did not differ significantly between the hyperimmune globulin group and the placebo group (5 infusions [interquartile range, 3 to 6 ] and 4 infusions [interquartile range, 3 to 6 ], respectively; $\mathrm{P}=0.60$ ).

\section{PRIMARY END POINT}

Intrauterine transmission occurred in 45 of 123 cases $(37 \%)$. Congenital infection was diagnosed before birth in 18 fetuses and at birth in 27 newborns. Three of the 40 newborns $(8 \%)$ who had tested negative for CMV when amniocentesis was performed were found at birth to be infected (Fig. 2). A total of 18 congenital infections occurred among the fetuses or newborns of the 61 


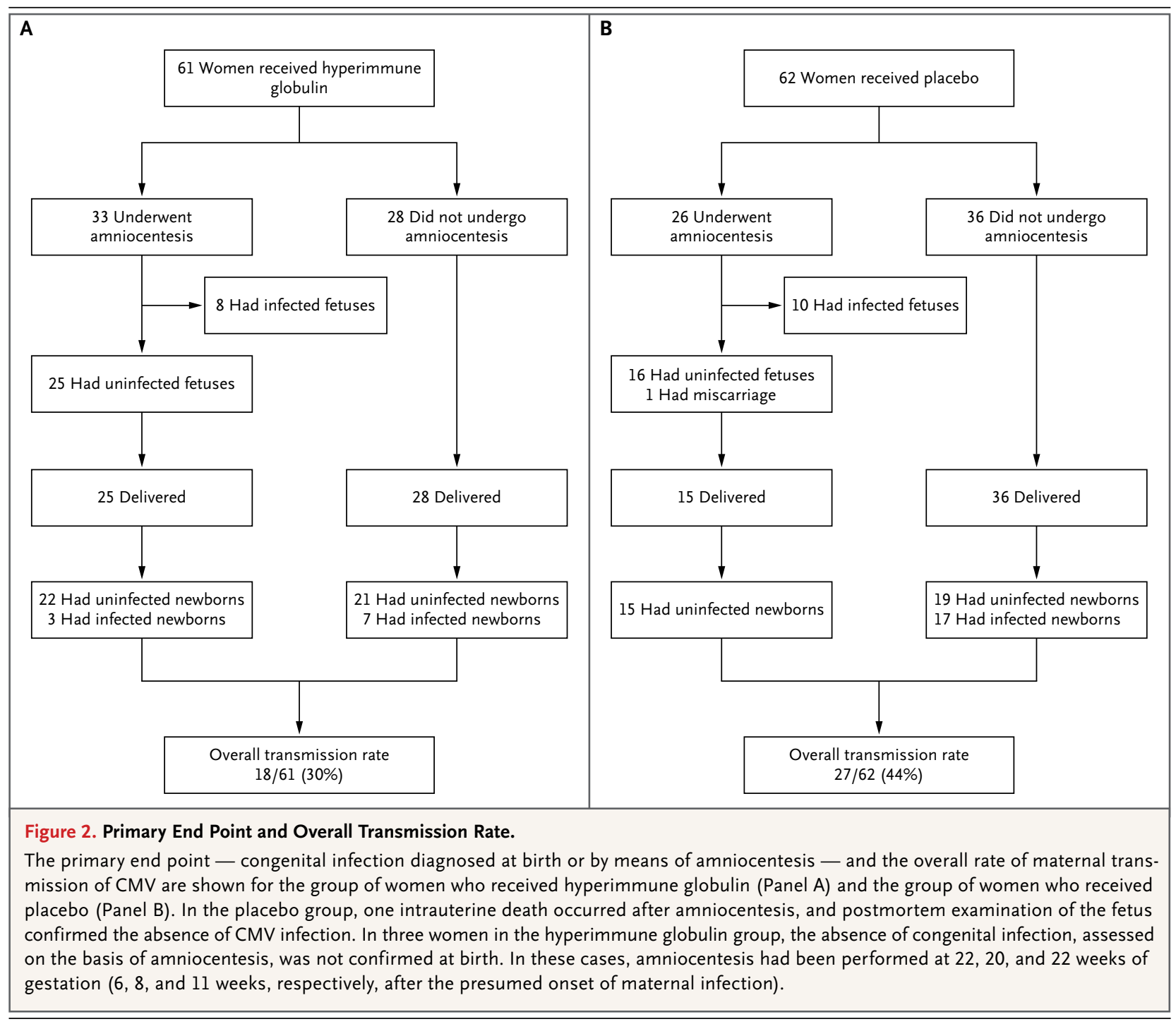

women in the hyperimmune globulin group (30\%), and 27 among the fetuses or newborns of the 62 women in the placebo group (44\%), for a difference of 14 percentage points ( $95 \%$ confidence interval, -3 to $31 ; \mathrm{P}=0.13)$. Of the 18 women in the hyperimmune globulin group who transmitted the virus, 9 of the mothers received a diagnosis of CMV during the first trimester and 9 during the second trimester; of the 27 women in the placebo group who transmitted the virus, 12 received a diagnosis of CMV during the first trimester and 15 during the second trimester. A nonsignificant difference in the transmission rate was observed when only fetuses or only newborns were included in the analysis and when only mothers who underwent seroconversion were included. No significant difference between the two groups was observed with respect to the viral DNA load in the amniotic fluid of infected fetuses or with respect to levels of viral DNA in urine or blood or virus-specific IgM in infected newborns (Table 2).

\section{IMMUNOLOGIC AND VIROLOGIC ANALYSES OF MATERNAL BLOOD}

No significant difference was observed between the two groups with respect to CMV-specific IgG and IgM, IgG avidity, or levels of neutralizing antibodies (as determined in human fibroblasts and ARPE-19 epithelial cells) (Table S1 in the 


\begin{tabular}{|c|c|c|c|}
\hline Variable & $\begin{array}{c}\text { Mothers Received } \\
\text { Hyperimmune Globulin }\end{array}$ & $\begin{array}{l}\text { Mothers Received } \\
\text { Placebo }\end{array}$ & P Value \\
\hline \multicolumn{4}{|l|}{ Fetuses } \\
\hline No. with infection & 8 & 10 & \\
\hline Viral DNA in amniotic fluid $-\log _{10}$ copies $/ \mathrm{ml}$ & & & 0.40 \\
\hline Median & 6.8 & 6.6 & \\
\hline Interquartile range & $5.20-7.48$ & $6.14-7.09$ & \\
\hline \multicolumn{4}{|l|}{ Newborns } \\
\hline No. with infection & 10 & 17 & \\
\hline Positive for viral DNA in blood — no. (\%) & $10(100)$ & $15(88)$ & 0.51 \\
\hline Viral DNA in blood - IU/ml & & & 0.38 \\
\hline Median & 1353 & 925 & \\
\hline Interquartile range & $200-13,457$ & $200-2061$ & \\
\hline Viral DNA in urine $-\log _{10}$ copies $/ \mathrm{ml}$ & & & 1.00 \\
\hline Median & 7.39 & 7.11 & \\
\hline Interquartile range & $5.91-7.85$ & $6.67-7.62$ & \\
\hline Positive for IgM — no./total no. tested (\%) & $4 / 9(44)$ & $4 / 16(25)$ & 0.39 \\
\hline
\end{tabular}

Supplementary Appendix). At the time of enrollment, all the women were already positive for VR1814-neutralizing antibodies (in epithelial cells), whereas AD169-neutralizing antibodies (in fibroblast cells) were not detected in 18 of 59 women $(31 \%)$ in the hyperimmune globulin group or in 20 of 62 women (32\%) in the placebo group. At study end, all the women in both groups were positive for AD169 neutralizing antibodies. The findings with respect to lymphocyte subpopulations, CMV-specific cell-mediated immunity, and level of CMV DNA in the blood were similar in the two groups (Table S1 in the Supplementary Appendix), as was the time to clearance of viral DNA from the blood (Fig. S1 in the Supplementary Appendix).

When the characteristics of women who transmitted the virus and those of women who did not transmit the virus were compared between the two study groups and within each study group, no significant difference was observed with respect to the week of gestation at the onset of infection, the number of weeks between the diagnosis of infection and treatment (Table S2 in the Supplementary Appendix), or any of the other immunologic or virologic variables investigated (Table S3 in the Supplementary Appendix).

\section{ADVERSE EVENTS}

A total of 20 adverse events were reported in 16 women, including 11 serious adverse events in 10 women. The serious adverse events in the hyperimmune globulin group were preterm delivery (4 women, at 25, 32, 33, and 33 weeks), intrauterine growth restriction and induction of preterm delivery ( 1 woman, at 36 weeks), intrauterine growth restriction (1 woman), and intrahepatic cholestasis of pregnancy and postpartum eclampsia (2 events in 1 woman). The serious adverse events in the placebo group were spontaneous abortion after amniocentesis, arthralgia of the upper and lower limbs, and pregnancyinduced hypertension (1 woman each). Adverse events in the hyperimmune globulin group included pruritus of the lower limbs ( 3 events in 1 woman), headache (1 woman), and vomiting (1 woman). Adverse events in the placebo group included asthenia (1 woman), headache (1 woman), and thrombocytopenia (2 events in 1 woman). Overall, obstetrical complications (preterm delivery, preeclampsia, and fetal growth restriction) were recorded in 7 of 53 women $(13 \%)$ in the hyperimmune globulin group who remained in the study until the time of delivery, as compared with 1 of 51 women (2\%) in the placebo group $(\mathrm{P}=0.06)$. 


\begin{tabular}{|c|c|c|c|c|}
\hline \multirow[t]{2}{*}{ Variable } & \multicolumn{2}{|c|}{$\begin{array}{l}\text { Newborns Whose Mothers } \\
\text { Received Hyperimmune Globulin }\end{array}$} & \multicolumn{2}{|c|}{$\begin{array}{l}\text { Newborns Whose Mothers } \\
\text { Received Placebo }\end{array}$} \\
\hline & $\begin{array}{l}\text { Infected } \\
(\mathrm{N}=10)\end{array}$ & $\begin{array}{l}\text { Uninfected } \\
(\mathrm{N}=38) \dagger\end{array}$ & $\begin{array}{l}\text { Infected } \\
(\mathrm{N}=17)\end{array}$ & $\begin{array}{l}\text { Uninfected } \\
(\mathrm{N}=30) \dagger\end{array}$ \\
\hline Prematurity - no. $\downarrow$ & 1 & 6 & 1 & 0 \\
\hline Fetal growth restriction - no. $\mathbb{\Omega}$ & 1 & 2 & 2 & 0 \\
\hline Microcephaly - no.9 & 1 & 2 & 2 & 0 \\
\hline Jaundice - no. & 1 & 5 & 2 & 2 \\
\hline Hearing deficits - no.\| & 0 & 2 & 1 & 1 \\
\hline Other symptoms or birth defects - no.*** & 2 & 4 & 0 & 2 \\
\hline$\geq 1$ Symptom or birth defect — no. (\%) & $3(30)$ & $10(26)$ & $4(24)$ & $5(17)$ \\
\hline \multicolumn{5}{|c|}{$\begin{array}{l}\text { There were no instances of hypotonia, petechiae, or hepatosplenomegaly in any of the newborns. } \\
\text { Only newborns with a known clinical outcome were included. } \\
\text { Premature birth was defined as birth before } 36 \text { weeks, } 6 \text { days of gestation. The infected infant in each group was bor } \\
\text { at } 36 \text { weeks of gestation. The six uninfected infants whose mothers had received hyperimmune globulin were born at } \\
25,32,33,33,35 \text {, and } 36 \text { weeks of gestation. } \\
\text { Fetal growth restriction was defined as less than the } 10 \text { th percentile for weight. } \\
\text { Microcephaly was defined as a head circumference that was less than the } 10 \text { th percentile. } \\
\text { Hearing deficits were identified on the basis of testing for otoacoustic emissions. } \\
\text { Among newborns whose mothers had received hyperimmune globulin, the other symptoms or birth defects were } \\
\text { hypoxemia ( } 1 \text { infant) and fundus oculi abnormalities ( } 1 \text { in in infected infants and hypoxemia ( } 2 \text { infants), respiratory dis- } \\
\text { tress (1), and sepsis (1) in uninfected newborns. Among newborns whose mothers had received placebo, the other } \\
\text { symptoms or birth defects were hypospadias and hydrocele ( } 1 \text { infant) and preauricular skin tags (1); both infants } \\
\text { were uninfected. }\end{array}$} \\
\hline
\end{tabular}

\section{CLINICAL OUTCOME IN NEWBORNS}

Overall, 104 women remained in the study until the time of delivery (Fig. 2). No significant differences with respect to sex, weight, gestational age at birth, or Apgar score were observed between newborns whose mothers had received hyperimmune globulin and newborns whose mothers had received placebo. The most frequent complication among babies born to mothers who had received hyperimmune globulin was prematurity (Table 3). Premature birth was recorded in 7 of 48 babies $(15 \%)$ born to mothers who had received hyperimmune globulin and in 1 of 47 babies $(2 \%)$ born to mothers who had received placebo $(\mathrm{P}=0.06)$. Six of the 7 premature babies born to mothers who had received hyperimmune globulin were not infected with CMV. Three infants born to mothers in the hyperimmune globulin group had a low birth weight (range, 1880 to $2170 \mathrm{~g}$ ), and 1 infant had an extremely low birth weight $(870 \mathrm{~g})$. Three of $10 \mathrm{CMV}$-infected newborns in the hyperimmune globulin group (30\%) and 4 of 17 in the placebo group (24\%) had symptoms at birth.

\section{OTHER SECONDARY END POINTS}

Preliminary analysis of fetal records indicated that there were no significant differences between the two study groups in ultrasonographic findings: 7 of 61 fetuses (11\%) in the hyperimmune globulin group and 10 of $62(16 \%)$ in the placebo group had transient or permanent abnormalities. Similarly, the median DNA viral load in 19 term placentas (10 from mothers in the hyperimmune globulin group and 9 from mothers in the placebo group) did not differ significantly between the two groups and was low in both groups (10 copies per $0.005 \mu \mathrm{g}$ [range, 10 to 10] and 16 copies per $0.005 \mu \mathrm{g}$ [range, 10 to 34], respectively).

\section{DISCUSSION}

This controlled study did not show a significant reduction in the rate of transmission of CMV infection among women receiving hyperimmune globulin as compared with women receiving placebo. Moreover, this study showed no effect of hyperimmune globulin on the activity of neutral- 
izing antibodies. Previous data showed that neutralizing antibodies, as measured in endothelial or epithelial cells with the use of the VR1814 CMV prototype, are directed primarily against the pentameric $\mathrm{gH} / \mathrm{gL} / \mathrm{pUL} 128 \mathrm{~L}$ complex ${ }^{17,18}$ and represent the major neutralizing component of human serum and commercial hyperimmune globulin. ${ }^{19,20}$ As confirmed in this study, these neutralizing antibodies are produced and peak very early after the onset of primary infection, without a clear difference between mothers who transmit the virus and mothers who do not. ${ }^{12,21}$ On the other hand, neutralizing antibodies against AD169 are slower to develop, ${ }^{12,21,22}$ and in our study, administration of hyperimmune globulin did not significantly modify their levels.

Similarly, hyperimmune globulin did not significantly modify maternal levels of DNA in the blood or the time to clearance of DNA from the blood, nor did it significantly modify DNA levels in placentas. No significant differences in the level of DNA in the blood were noted in either study group between women who transmitted the virus and those who did not - a finding that was in agreement with results of a previous study. ${ }^{23}$ These findings do not support the explanation that hyperimmune globulin could act by reducing the maternal or placental viral load through a direct neutralization effect, as hypothesized by Nigro and colleagues. ${ }^{5}$ Finally, administration of hyperimmune globulin apparently had no effect on the virus-specific T-cell responses.

One challenging aspect of the CHIP study was establishing the presumed onset of primary infection. Relying on the experience of the two reference diagnostic centers, in Pavia and Bologna, ${ }^{24,25}$ we defined the onset of primary infection as the reported date of the onset of symptoms or signs when those reports were in agreement with serologic results. In this study, symptoms and signs were reported by about $60 \%$ of the women. Other studies have shown similar rates. ${ }^{26-28}$ In addition, on the basis of our experience with the assays used in this study, when the results of serologic tests reached prespecified levels (i.e., an IgM ratio higher than 10 times the cutoff value or IgG avidity lower than $15 \%)$, the onset was assumed to have occurred during the previous 6 weeks. CMV antigenemia was another criterion, since its detection is restricted to the early phase of primary infection in immunocompetent persons. ${ }^{29}$ Altogether, the above criteria were considered to be strict enough to reasonably exclude infections acquired earlier than 6 weeks before enrollment.

Another critical point was that we excluded from our analysis infections that occurred before conception, since the risk of fetal infection associated with maternal infection acquired before pregnancy is lower than that reported after primary infection during the first trimester of gestation (approximately 5\% vs. approximately $40 \%{ }^{24,30,31}$ We excluded those infections by restricting the enrollment to women with primary infection acquired after the fifth week of pregnancy. In the study by Nigro et al, ${ }^{5}$ the median week of gestation at the time of maternal infection was significantly earlier in the group of women who received prophylactic hyperimmune globulin treatment than in the group of women who did not receive hyperimmune globulin (14 weeks vs. 20 weeks) $(\mathrm{P}<0.01)$, and the rate of transmission was significantly lower among the pretreated women as well.

In this study three cases of false negative prenatal diagnosis were observed in the hyperimmune globulin group. False negative results have been reported previously. ${ }^{32,33}$

A recent preliminary evaluation of the safety and efficacy of standard preparations of intravenous immune globulin in pregnant women with primary CMV infection showed an increase in CMV IgG titers and avidity. ${ }^{34}$ In that study, 27 of 67 newborns (40\%) born to mothers who had been treated with intravenous immune globulin were found to be infected at birth. However, it is not clear whether the lower preventive efficacy of standard immune globulin as compared with hyperimmune globulin is due to differences between study protocols or immune globulin preparations. ${ }^{35}$

Finally, a higher number of serious adverse events were recorded among women who received hyperimmune globulin and among their newborns than among women who received placebo and their newborns. The administration of intravenous immune globulin can have adverse effects. Fortunately, most adverse events have been mild. ${ }^{36}$ Although the higher rate of preterm deliveries observed among women in the hyperimmune globulin group raises some concerns, at the moment there is no definitive indication that preterm birth is a hyperimmune globulin-related adverse event. 
From the cost-effectiveness point of view, our results (a 32\% relative decrease in the transmission rate and no significant difference in the clinical outcome at birth) represent less than the $47 \%$ reduction in congenital CMV that has been considered by some to be the threshold for recommending screening for and treatment of primary maternal infection in pregnancy as a costeffective strategy. ${ }^{37}$

Currently, two randomized, phase 3 studies of the prevention of congenital infection are under way. One, sponsored by Biotest, is being conducted in Europe, ${ }^{38}$ and the second, sponsored by the Eunice Kennedy Shriver National Institute of Child Health and Human Development, is ongoing in the United States (ClinicalTrials.gov number, NCT01376778). The hope is that the results of these studies will further our understanding of the efficacy and safety of hyperimmune globulin administration as a means of preventing congenital CMV infection.

In conclusion, this randomized, placebo-con- trolled trial of virus-specific hyperimmune globulin for the prevention of congenital CMV infection showed no significant between-group difference in either the primary outcome or the secondary clinical and biologic outcomes examined. However, because the effect was smaller than expected, the power to detect such a difference was small (33\%). About three times as many patients would have had to have been enrolled for the study to have had the power to detect a 14-percentage-point difference in the primary outcome.

Supported by a grant (FARM7J4HCH) from Agenzia Italiana del Farmaco.

Disclosure forms provided by the authors are available with the full text of this article at NEJM.org.

We thank all the women who participated in the trial, the pharmacists and nurses who made the study possible, Elena Percivalle and Chiara Fornara from Fondazione IRCCS Policlinico San Matteo of Pavia for their technical expertise, and Daniela Sartori and Laurene Kelly for assistance with the preparation of the manuscript.

This article is dedicated to the memory of Umberto Nicolini, who made a major contribution to the study of CMV infection in pregnancy and who died soon after the design of this study had been completed.

The authors' affiliations are as follows: the Departments of Obstetrics and Gynecology (M.G.R., A.S., A.A.), Virology Unit (M.F.), Statistics and Biometrics (C.K.), and Experimental Research Laboratories (G.G.), Fondazione Istituto di Ricovero e Cura a Carattere Scientifico (IRCCS) Policlinico San Matteo, and Clinical Microbiology Unit, Clinical-Surgical, Diagnostic and Pediatric Sciences, University of Pavia (V.R.), Pavia; Operative Unit of Microbiology, Department of Specialized, Experimental, and Diagnostic Medicine (T.L.), Operative Unit of Obstetrics and Prenatal Medicine, Department of Medical Surgical Sciences (B.G., N.R.), and Operative Unit of Microbiology (L.G.), St. Orsola-Malpighi General Hospital, University of Bologna, Bologna; the Department of Woman, Mother, and Neonate (E.F.), Buzzi Children's Hospital, University of Milan, and Emergency Department of Obstetrics and Gynecology, Fondazione IRCCS Ca' Granda Ospedale Maggiore Policlinico (A.K.), Milan; the Department of Medical, Surgical and Health Sciences, University of Trieste, Trieste (S.G.); the Department of Interdisciplinary Surgical and Medical Sciences, University of Milano-Bicocca, San Gerardo Hospital, Monza (P.V.); the Department of Surgical Sciences, University of Turin, Turin (T.T.); and the Departments of Obstetrics and Gynecology, University of Brescia, Brescia (T.F.) - all in Italy.

REFERENCES

1. Cannon MJ, Davis KF. Washing our hands of the congenital cytomegalovirus disease epidemic. BMC Public Health 2005;5:70.

2. de Vries JJC, Vossen ACTM, Kroes ACM, van der Zeijst BAM. Implementing neonatal screening for congenital cytomegalovirus: addressing the deafness of policy makers. Rev Med Virol 2011;21:5461.

3. Dollard SC, Grosse SD, Ross DS. New estimates of the prevalence of neurological and sensory sequelae and mortality associated with congenital cytomegalovirus infection. Rev Med Virol 2007;17:35563.

4. Fowler KB, Stagno S, Pass RF, Britt WJ, Boll TJ, Alford CA. The outcome of congenital cytomegalovirus infection in relation to maternal antibody status. $\mathrm{N}$ Engl J Med 1992;326:663-7.

5. Nigro G, Adler SP, La Torre R, Best
AM. Passive immunization during pregnancy for congenital cytomegalovirus infection. N Engl J Med 2005;353:1350-62. 6. Buxmann $\mathrm{H}$, Stackelberg OM, Schlößer RL, et al. Use of cytomegalovirus hyperimmunoglobulin for prevention of congenital cytomegalovirus disease: a retrospective analysis. J Perinat Med 2012;40:439-46.

7. Nigro G, Adler SP, Parruti G, et al. Immunoglobulin therapy of fetal cytomegalovirus infection occurring in the first half of pregnancy - a case-control study of the outcome in children. J Infect Dis 2012;205:215-27.

8. Visentin S, Manara R, Milanese L, et al. Early primary cytomegalovirus infection in pregnancy: maternal hyperimmunoglobulin therapy improves outcomes among infants at 1 year of age. Clin Infect Dis 2012;55:497-503.

9. Japanese Congenital Cytomegalovirus
Infection Immunoglobulin Fetal Therapy Study Group. A trial of immunoglobulin fetal therapy for symptomatic congenital cytomegalovirus infection. J Reprod Immunol 2012;95:73-9.

10. Clinicaltrials.gov. Efficacy study of human cytomegalovirus (HCMV) hyperimmune globulin to prevent congenital HCMV infection (CHIP) (http://clinicaltrials .gov/ct2/show/record/NCT00881517).

11. Italian Medicines Agency (AIFA) Research \& Development Working Group. Feasibility and challenges of independent research on drugs: the Italian medicines agency (AIFA) experience. Eur J Clin Invest 2010;40:69-86.

12. Gerna G, Sarasini A, Patrone M, et al. Human cytomegalovirus serum neutralizing antibodies block virus infection of endothelial/epithelial cells, but not fibroblasts, early during primary infection. J Gen Virol 2008;89:853-65. 
13. Gerna G, Revello MG, Percivalle E, Morini F. Comparison of different immunostaining techniques and monoclonal antibodies to the lower matrix phosphoprotein (pp65) for optimal quantitation of human cytomegalovirus antigenemia. J Clin Microbiol 1992;30:1232-7.

14. Gerna G, Revello MG, Percivalle E, Zavattoni M, Parea M, Battaglia M. Quantification of human cytomegalovirus viremia by using monoclonal antibodies to different viral proteins. J Clin Microbiol 1990;28:2681-8.

15. Gabrielli L, Bonasoni MP, Santini D, et al. Congenital cytomegalovirus infection: patterns of fetal brain damage. Clin Microbiol Infect 2012;18(10):E419-E427.

16. Lozza L, Lilleri D, Percivalle E, et al. Simultaneous quantification of human cytomegalovirus (HCMV)-specific CD4+ and $\mathrm{CD} 8+\mathrm{T}$ cells by a novel method using monocyte-derived HCMV-infected immature dendritic cells. Eur J Immunol 2005; 35:1795-804.

17. Macagno A, Bernasconi NL, Vanzetta $\mathrm{F}$, et al. Isolation of human monoclonal antibodies that potently neutralize human cytomegalovirus infection by targeting different epitopes on the gH/gL/UL128131A complex. J Virol 2010;84:1005-13

18. Lilleri D, Kabanova A, Lanzavecchia A, Gerna G. Antibodies against neutralization epitopes of human cytomegalovirus gH/gL/pUL128-130-131 complex and virus spreading may correlate with virus control in vivo. J Clin Immunol 2012;32: 1324-31.

19. Lilleri D, Kabanova A, Revello MG, et al. Fetal human cytomegalovirus transmission correlates with delayed maternal antibodies to gH/gL/pUL128-130-131 complex during primary infection. PLoS One 2013;8(3):e59863.

20. Fouts AE, Chan P, Stephan J-P, Vandlen $\mathrm{R}$, Feierbach B. Antibodies against the gH/gL/UL128/UL130/UL131 complex comprise the majority of the anti-cytomegalovirus (anti-CMV) neutralizing antibody response in CMV hyperimmune globulin. J Virol 2012;86:7444-7.
21. Revello MG, Gerna G. Human cytomegalovirus tropism for endothelial/epithelial cells: scientific background and clinical implications. Rev Med Virol 2010, 20:136-55.

22. Eggers M, Bäder U, Enders G. Combination of microneutralization and avidity assays: improved diagnosis of recent primary human cytomegalovirus infection in single serum sample of second trimester pregnancy. J Med Virol 2000;60:32430.

23. Revello MG, Lilleri D, Zavattoni M, et al. Lymphoproliferative response in primary human cytomegalovirus (HCMV) infection is delayed in HCMV transmitter mothers. J Infect Dis 2006;193:269-76.

24. Revello MG, Fabbri E, Furione M, et al. Role of prenatal diagnosis and counseling in the management of 735 pregnancies complicated by primary human cytomegalovirus infection: a 20-year experience. J Clin Virol 2011;50:303-7.

25. Guerra B, Simonazzi G, Lazzarotto T, et al. Impact of diagnostic and confirmatory tests and prenatal counseling on the rate of pregnancy termination among women with positive immunoglobulin $M$ antibody titers. Am J Obstet Gynecol 2007;196(3):221.e1-221.e6.

26. Revello MG, Gerna G. Diagnosis and management of human cytomegalovirus infection in the mother, fetus, and newborn infant. Clin Microbiol Rev 2002;15 680-715.

27. Gindes L, Teperberg-Oikawa M, Sherman D, Pardo J, Rahav G. Congenital cytomegalovirus infection following primary maternal infection in the third trimester. BJOG 2008;115:830-5.

28. Nigro G, Anceschi MM, Cosmi EV Clinical manifestations and abnormal laboratory findings in pregnant women with primary cytomegalovirus infection. BJOG 2003;110:572-7.

29. Revello MG, Zavattoni M, Sarasini A Percivalle E, Simoncini L, Gerna G. Human cytomegalovirus in blood of immunocompetent persons during primary infection: prognostic implications for pregnancy. J Infect Dis 1998;177:11705.

30. Picone O, Vauloup-Fellous C, Cordier AG, et al. A series of 238 cytomegalovirus primary infections during pregnancy: description and outcome. Prenat Diagn 2013; 33:751-8.

31. Revello MG, Gerna G. Pathogenesis and prenatal diagnosis of human cytomegalovirus infection. J Clin Virol 2004; 29:71-83.

32. Revello MG, Furione M, Zavattoni M, et al. Human cytomegalovirus (HCMV) DNAemia in the mother at amniocentesis as a risk factor for iatrogenic HCMV infection of the fetus. J Infect Dis 2008; 197:593-6.

33. Enders G, Bäder U, Lindemann L, Schalasta G, Daiminger A. Prenatal diagnosis of congenital cytomegalovirus infection in 189 pregnancies with known outcome. Prenat Diagn 2001;21:362-77. [Erratum, Prenat Diagn 2001;21:605.]

34. Polilli E, Parruti G, D’Arcangelo F, et al. Preliminary evaluation of the safety and efficacy of standard intravenous immunoglobulins in pregnant women with primary cytomegalovirus infection. Clin Vaccine Immunol 2012;19:1991-3.

35. Adler SP, Nigro G. Findings and conclusions from CMV hyperimmune globulin treatment trials. J Clin Virol 2009;46: Suppl 4:S54-S57.

36. Pierce LR, Jain N. Risks associated with the use of intravenous immunoglobulin. Transfus Med Rev 2003;17:241-51.

37. Cahill AG, Odibo AO, Stamilio DM, Macones GA. Screening and treating for primary cytomegalovirus infection in pregnancy: where do we stand? A decisionanalytic and economic analysis. Am J Obstet Gynecol 2009;201(5):466.e1-466.e7.

38. Interim analysis of the Cytotec Phase III trial in congenial cytomegalovirus (CMV) infection shows clear indication of efficacy. Press release of Biotest, January 27, 2011 (http://www.biotest.de/ww/en/ pub/investor_relations/news/newsdetails .cfm?newsID=1025191).

Copyright (C) 2014 Massachusetts Medical Society. 